\title{
Triagem Diagnóstica no Processo de Avaliação Neuropsicológica Interdisciplinar
}

\author{
Diagnosis Screening in the Interdisciplinary Neuropsychological \\ Assessment Process
}

\author{
Anna Carolina Rufino Navatta ${ }^{b}$, Maria Fernanda Fonseca $^{a}$, \\ Mauro Muszkat ${ }^{a}$ \& Mônica Carolina Miranda ${ }^{a, b, *}$ \\ ${ }^{a}$ Universidade Federal de São Paulo \& ${ }^{b}$ AFIP, Associação Fundo de Incentivo a Psicofarmacologia
}

\begin{abstract}
Resumo
O presente artigo apresenta o modelo de triagem diagnóstica interdisciplinar de um núcleo assistencial neuropsicológico infantil. O modelo de triagem está fundamentado numa perspectiva bio-psico-social, que consiste na entrevista inicial com as crianças em grupo realizado uma equipe interdisciplinar. $\mathrm{O}$ modelo se justifica pelo fato de que essa percepção inicial do neuropsicólogo, através do modelo tradicional, é demorado, caro, e às vezes ineficiente para determinados pacientes neurológicos. A proposta de que possa direcionar o processo, gerando um ponto de partida para a avaliação neuropsicológica da criança. A implementação deste procedimento em serviços ambulatoriais propicia benefícios amplos que envolvem não só a redução de custos, como também a humanização do atendimento ao paciente.

Palavras-chave: Triagem; Diagnóstico; Neuropsicologia; Interdisciplinaridade.
\end{abstract}

\begin{abstract}
This article aims at presenting a model of interdisciplinary diagnosis screening in a child care neuropsychological group. The biopsychosocial perspective is the base of the diagnosis screening, which consists of an initial interview with the children in groups carried by an interdisciplinary staff. The model is justified for the fact that this initial perception of the neuropsychologist, through the traditional model, is time-consuming, costly and, inefficient for most neurology patients. The proposal is that this can direct the assessment, generating a starting point for the neuropsychology evaluation. Considering the patient's decrease of emotional loses, the integrated diagnosis, and the financial aspect, we conclude that the implementation of this procedure in clinic services promotes benefits which involve not only the reduction of costs, but also the humanization of the patient's care.

Keywords: Screening; Diagnosis; Neuropsychology; Interdisciplinary.
\end{abstract}

O procedimento conhecido como triagem em serviços assistenciais de saúde, em geral caracteriza-se pela seleção e escolha de pacientes que se enquadrem e que possam ser beneficiados pelo atendimento prestado em uma determinada instituição.

Atualmente a proposta do Núcleo de Atendimento Neuropsicológico Infantil (NANI) está centrada no diagnóstico interdisciplinar. O NANI é um serviço, vinculado ao Departamento de Psicobiologia da Universidade Federal de São Paulo (UNIFESP) e atende gratuitamente crianças com transtornos do neurodesenvolvimento.

Conforme descreve Miranda (2006) a avaliação infantil, à luz da neuropsicologia do desenvolvimento, é um processo psicodiagnóstico que tem como foco a relação cérebro-comportamento. Nesta ótica as dimensões do comportamento constituem uma rede dos sistemas emocionais, cognitivos e de controle intimamente relaciona-

\footnotetext{
* Endereço para correspondência: CPN/NANI, Rua Embau, 54, São Paulo, SP, CEP 04039-060. E-mail: mirandambr@yahoo.com.br
}

dos com o funcionamento cerebral. Neste contexto, a participação de diferentes profissionais (psicólogo, neuropsicólogo, psicopedagogo, fonoaudiólogo, terapeuta ocupacional, médico, entre outros) configura uma forma de se trabalhar dentro do conceito da troca e da sobreposição de experiências, compartilhando vivências e conhecimento entre os profissionais de diferentes áreas do saber visando integração (Miranda \& Muzskat, 2007).

A seleção da população recebida no NANI ocorre através de uma pré-triagem, realizada pela assistente social. Seu objetivo é identificar os casos que se enquadrem à demanda de atendimentos oferecidos no âmbito do diagnóstico e da pesquisa existentes no serviço, além da obtenção de informações da condição socioeconômica da família. Após essa fase de pré-triagem, é agendado então o que denominamos de triagem diagnóstica, destinada a identificar e explorar mais detalhadamente a queixa trazida pela família.

Diversas pesquisas descrevem os benefícios do atendimento interdisciplinar grupal no tratamento de aspectos comportamentais infantis. Também são relatadas na li- 
teratura algumas experiências institucionais em grupos, como psicodiagnóstico infantil e procedimentos lúdicos (Avoglia, 2006; Santos, 1987; Teodoro \& Horta, 2004).

A avaliação psicológica infantil é um processo e, portanto, pressupõe alguns passos: entrevista inicial, observações lúdicas, planejamento da avaliação, seleção de instrumentos, análise e integração dos dados, seja esse processo individual ou em grupo (Costa, Azambuja, Portuguez, \& Costa 2004; Cunha, 2000; Miranda, 2006). A avaliação neuropsicológica na infância pode ser expressa quantitativamente e qualitativamente. Do ponto de vista quantitativo, são utilizados testes psicométricos e neuropsicológicos, organizados em baterias fixas ou flexíveis, os resultados refletem os principais ganhos ao longo do desenvolvimento e têm o objetivo de determinar o nível evolutivo específico da criança (Costa et al., 2004; Gilmour, 2005; Miranda, 2006).

Gilmour (2005) destaca que a avaliação apresenta, no entanto, limitações no retrato compreensivo de diversas funções cognitivas específicas na criança, em vista da capacidade destas em melhorar seu desempenho durante o processo devido à neuroplasticidade e ao uso de estratégias compensatórias.

Assim como no psicodiagnóstico infantil, na avaliação neuropsicológica da criança costuma-se entrevistar os pais. Após a entrevista, é agendado o primeiro contato com a criança, que pode ser por meio de uma entrevista lúdica seguidos então da seleção e utilização de instrumentos de exame, levantamento quantitativo e qualitativo dos dados, formulação de inferências pela integração dos dados, tendo como pontos de referência as hipóteses iniciais e os objetivos do exame, comunicação de resultados e encerramento do processo. Tais procedimentos requerem inúmeros encontros e sessões muitas vezes individualizadas (Cunha, 2000).

No entanto, Carey e Konkol (2001) destacam que a viabilidade da avaliação neuropsicológica tradicional em centros de saúde, com diversos encontros individuais e aplicação de diversas testagens e procedimentos, vem sendo questionada por administradores da área da saúde em função do custo financeiro que esta representa, propondo, assim um processo multidisciplinar, economicamente eficiente, na avaliação das crianças.

Como já citamos, o planejamento inicial do processo de avaliação inicia-se com a entrevista clínica e observação da criança, mas não há modelos descritos em literatura que possam reduzir o tempo nessa etapa, ou seja, um modelo de triagem com um enfoque diagnóstico e principalmente, que pudesse ser realizado em grupo.

A importância de modelos estruturados de triagem em grupo se justifica pelo fato de que essa percepção inicial do neuropsicólogo, através do modelo tradicional é demorado, caro, e às vezes ineficiente para determinados pacientes neurológicos (Carey \& Konkol, 2001).

A proposta aqui não é substituir a avaliação individualizada e com base em testes, mas sim direcionar esta, gerando um ponto de partida para a investigação neuro- psicológica da criança. A partir de estudos e propostas das diversas áreas de conhecimento (Psicologia, Neuropsicologia, Psicopedagogia, Medicina, Fonoaudiologia, entre outras) foram estabelecidos objetivos e procedimentos específicos para a triagem diagnóstica.

Justificamos aqui a apresentação desse modelo implementado em nosso núcleo, e ressaltamos a importância de pesquisas que comprovem a aplicabilidade de procedimentos como esse. Segue a descrição desta abordagem levando a compreensão de como, em nossa experiência, esse modelo permitiu o estabelecimento de hipóteses diagnósticas e dos métodos de investigação que serão utilizados em cada caso.

\section{Método}

\section{Descrição da Triagem Diagnóstica Com as Crianças}

São formados grupos de quatro ou cinco crianças com idades entre 5 a 14 anos, que participam de várias atividades, com objetivos bem definidos que detalharemos a seguir.

A triagem diagnóstica envolve a participação de pelo menos 2 ou 3 profissionais de áreas diferentes (psicólogo, neuropsicólogo, psicopedagogo, fonoaudiólogo, médico, entre outros), os quais anotam sistematicamente no Protocolo de Triagem Diagnóstico (Anexo A) os comportamentos observados.

Serão descritas a seguir cada uma das etapas dessa triagem, seus objetivos, as funções cognitivas e aspectos afetivo-emocionais avaliados.

Acolhimento. Por tratar-se do primeiro encontro entre as crianças e profissionais da equipe, busca-se esclarecer a criança sobre a sua presença no serviço e informar o que ocorrerá durante o processo de avaliação neuropsicológica que acontecerá posteriormente. Muitos autores descrevem a necessidade de ajuda e entrega com que o paciente chega para o primeiro contato com o psicólogo e pontuam, que a atitude de respeito, aceitação livre de críticas, valorização e empatia do profissional contribuem para a proximidade e vínculo pertinentes ao processo psicodiagnóstico (Cunha, 2000).

O objetivo aqui é a avaliação de aspectos cognitivos e afetivo-emocionais. Por exemplo, se a criança se mostra triste, apática, o vínculo com os examinadores; aspectos do comportamento como: agressividade, hiperatividade, comportamento opositor, entre outros. Essa observação do comportamento tem como principal objetivo comparar os dados que os pais trazem da criança, pois recebemos um número considerável de crianças com queixas de hiperatividade, comportamento opositor, entre outros, que muitas vezes se contrapõe ao que observamos nesse processo de triagem. No protocolo de triagem essa observação é realizada em todas as atividades durante esse processo.

Observa-se ainda a apresentação pessoal, se conhece o motivo de sua presença na instituição (por exemplo, é comum respostas do tipo "porque sou burro e não consi- 
go aprender" que denotam estigmatização); aspectos da linguagem oral (trocas articulatórias, entonação da voz, velocidade da fala, compreensão).

Apresentação. Em seguida, com todos em pé, é solicitado que as crianças e os profissionais se apresentem para o grupo, falando seu nome, idade, dados pessoais, série escolar, dados familiares, e noções temporais como dia, mês e ano, dentre outras informações. Esta etapa é importante para a continuidade do processo anterior, mas é também objetivos importantes alcançados, pois é possível analisar dados do desenvolvimento neuropsicológico importantes como o fato da criança ter noção temporal, de auto-referência, a memória de longo-prazo (lembrar dados autobiográficos), capacidade de atenção e concentração na atividade proposta.

Um exemplo de sintomas vistos em alguns quadros de transtornos do desenvolvimento, como a hiperatividade, no qual a criança pode apresentar alterações quanto à auto-referência ou mesmo orientação espaço-temporal, não sendo capaz de se situar quanto ao tempo e espaço, mesmo apresentando idade e condições cognitivas aparentemente adequadas (Barkley, 2008).

Dinâmica da Bola. Após a apresentação propomos uma atividade lúdica com uma bola, no qual as crianças em pé são posicionadas em círculo juntamente com os profissionais, são orientadas a jogar a bola de uma para a outra, falando o seu próprio nome quando recebem a bola e o nome do colega para o qual está repassando, as jogadas são realizadas várias vezes. Aqui podem ser observadas características peculiares das crianças, algumas apresentam dificuldades de recordar os nomes, outras jogam somente para a mesma pessoa repetidamente, dificuldades motoras ao pegar a bola, entre outras. Depois disso, ainda na mesma atividade, ocorre uma contagem de números na ordem crescente e decrescente, também realizada com jogada da bola de um para outro dando seqüência a numeração, a cada momento que joga a bola para outro componente do grupo fala o número seguinte ou anterior. Alguns conseguem, outros não, para tanto temos que ficar atentos às diferenças de idade e o potencial de conhecimento.

As habilidades aritméticas são muito importantes para a escolarização formal, sendo que quando alteradas podem comprometer o desempenho acadêmico das crianças e até caracterizar distúrbios neuropsicológicos importantes, tais como a discalculia. Além disso, por se tratar de uma atividade em grupo, é possível perceber como se posicionam e seu desempenho diante de outros, identificando atitudes que possam comprometer seu potencial cognitivo e relacional que justifiquem um comportamento alterado, desatento ou hiperativo diante do grupo.

São aspectos importantes, pois, em crianças com Transtorno do Déficit de Atenção/Hiperatividade, por exemplo, muitas vezes elas não memorizam os nomes dos colegas, pois não mantém o foco atencional. Podem também não ser capazes de permanecer no jogo durante o tempo estabelecido, não respeitando as regras e os limites, se mostrando agitadas, com comportamentos impulsivos, como por exemplo: interromper o outro, falar no lugar do outro, etc. O mesmo ocorre com crianças com Transtorno Opositor Desafiador, que é uma comorbidade freqüente do TDAH (Rohde, Barbosa, Tramontina, \& Polanczyk, 2000; Souza, Serra, Mattos, \& Franco, 2001).

Já crianças com transtornos de aprendizagem podem mostrar-se isoladas, desenvolver baixa auto-estima e evitar a exposição ao grupo, o que se deve as constantes dificuldades encontradas no âmbito das tarefas de conteúdo escolar, como por exemplo, a leitura em voz alta, ou execução de exercícios na lousa.

Momento Lúdico. A quarta etapa é a apresentação da caixa lúdica às crianças, que são incentivadas a estabelecer brincadeiras e jogos com os objetos ali presentes. A caixa lúdica contém diversos itens como famílias de bonecos de pano e de animais de plástico; carrinhos; aviõezinhos; objetos de cozinha; folhas; canetas, giz e lápis coloridos; etc. São evitados objetos pontiagudos como jogo de varetas, tesouras, entre outros, visando prevenção de acidentes, visto que crianças com TDAH, por exemplo, apresentam comportamentos impulsivos, dificuldade do controle inibitório e agitação psicomotora. Cabe ressaltar que uma boa triagem diagnóstica não se estabelece através da quantidade de estímulos disponibilizados. Efron, Fainberg, Kleiner, Sigal e Woscoboinik (1976) mencionam que uma quantidade excessiva de material lúdico distrai e confunde o entrevistado, sendo desnecessária.

Diversos autores já explicitaram o valor da observação lúdica como parte integrante do psicodiagnóstico. Durante as brincadeiras e jogos, a criança estrutura a representação de conflitos básicos, além de suas principais defesas e fantasias de doença e cura, o que propicia um panorama sobre seu funcionamento mental, sendo o brincar considerado como sua maneira característica de expressão, como a fala o é para o adulto (Efron et al., 1976; Aberastury, 1962 citado por Trinca, 1984). Além disso, observa-se também o comportamento da criança (agitado, tranqüilo, concentrado, entre outros) nesse tipo de atividade.

Produção Gráfica. Por último solicitamos a produção de desenhos livres, seguido da narração pela criança da estória destes, caso já esteja alfabetizada ela mesma escreverá a estória. Esta avaliação tem vários objetivos, que vão além da técnica projetiva, que analisa os aspectos afetivo-emocionais já bem discutidos em literatura: (a) a escrita - permite analisar o desenvolvimento da linguagem receptiva e expressiva, o significado da escrita para a criança, se reconhece o valor sonoro, o processo gráfico das letras, realizando, assim, uma sondagem das hipóteses de escrita, identificando desta forma o nível de desenvolvimento apresentado; (b) aspectos do 
desenvolvimento cognitivo referente à produção gráfica, fase do desenvolvimento do grafismo (Mèredieu, 2006), pressão do lápis, motricidade, conhecimento de cores e formas.

No entanto, a produção gráfica vem se mostrando também um recurso muito útil na detecção de aspectos afetivos, de ordem familiar como desagregação e inadequação, que são retratados pelas crianças. O conteúdo manifesto no desenho e estória da criança em triagem, assim como os comportamentos apresentados no grupo, pode auxiliar no planejamento do processo diagnóstico de forma singular, visto que complementam ou contradizem os dados obtidos na anamnese com os pais que veremos mais detalhadamente na apresentação de casos.

Concluído o desenho e a estória é realizada uma exploração de leitura através de letras, sílabas, palavras, frases de acordo com o desempenho de cada criança. Assim podemos já identificar também a fase de leitura.

Por fim, verifica-se a competência da aritmética com a realização de contas de adição, subtração, multiplicação e divisão, sempre considerando a idade cronológica e o seu desenvolvimento. Nessa atividade é possível verificar as habilidades de compreensão e contagem dos números, de calculo, de resolver problemas, identificar a operação, uso de calculo mental, retenção da informação, memória, entre outras. Nesse item da triagem temos a oportunidade de constatar traumas e dificuldades apresentadas no ambiente escolar, quase sempre relatados na anamnese e manifestados na oportunidade da atividade em grupo, onde o foco atencional, iniciativa e o comportamento de modo geral que podem determinar uma condição aos resultados no processo de ensinoaprendizagem.

Tais tarefas também permitem analisar o desenvolvimento de funções cognitivas como a viso-construção, desenvolvimento pensamento concreto/abstrato. Em crianças com queixas de dificuldades de aprendizagem essa etapa é essencial, pois permitem verificarmos a fase de aprendizagem da criança, dificuldades viso-motoras que interferem com o desenvolvimento da escrita, por exemplo. Em crianças com queixas de hiperatividade, desatenção, essa etapa permite analisar se há indicadores de dificuldade de aprendizagem.

\section{A Entrevista com os Pais/Responsáveis}

A entrevista inicial é de suma importância e na perspectiva da neuropsicologia do desenvolvimento, essa etapa do processo de avaliação neuropsicológica permite a detalhada coleta de informações: como antecendentes gestacionais, parto, desenvolvimento nos primeiros anos de vida, grau de dependência e independência nas atividades diárias (em casa, na escola), o processo de alfabetização, as dificuldades cognitivas (atenção, linguagem), distúrbios sensoriais, domínio temporal, conceitual, hábitos, fatores emocionais, de comportamento e as condições da família. Nesta etapa é importante o conhecimento do examinador acerca do espectro de distúrbios do desenvolvimento, na medida em que direcionará a investigação a partir da queixa. Por exemplo, em casos de queixas de agitação e dispersão, é importante que o examinador investigue o padrão persistente de desatenção e/ou hiperatividade, se estes sintomas estão presentes em pelo menos dois contextos, entre outros aspectos, que definem e caracterizam o Transtorno do Déficit de Atenção e Hiperatividade (TDAH), afastando assim outras causas, como de presença de sintomas de hiperatividade em decorrência de uma desestruturação da dinâmica familiar. Rohde e Mattos (2003) propõem aspectos a serem levantados na anamnese nesses casos.

Após a coleta dos dados obtidos da anamese e da observação lúdica da criança, esses são discutidos em equipe, e essa fase tem como objetivo determinar a hipótese inicial. Vimos que, muitas vezes, os dados são conflitantes ou discordantes entre a queixa trazida e o que se observa na criança nesse processo. E permite, além dos fatores expostos, entender de que maneira se da à relação entre aspectos estruturais ligados à maturidade ou lesões de áreas cerebrais envolvidas; tanto na percepção (áreas primárias e associativas) quanto na execução e planejamento de tarefas (áreas motoras e pré-frontais); e aspectos fluidos ligados à modificação de padrões motores, psíquicos e comportamentais. Estes, vistos diante dos desafios comuns na vida da criança, como a criatividade, solidariedade no brincar e partilhar, e a possibilidade de alterar modelos fixos e rígidos de interação interpessoal (Miranda, 2006).

Como vimos anteriormente, o exame neuropsicológico na infância é um processo e, portanto, pressupõe alguns passos ou etapas que em nosso caso inicia-se a partir da triagem diagnóstica, pois direciona o planejamento inicial da avaliação, a seleção adequada dos instrumentos ou técnicas da avaliação (quantitativa e qualitativa) e o estabelecimento da hipótese diagnóstica.

Veremos abaixo alguns casos ilustrativos que justificam a utilização deste método de triagem diagnóstica, assim como é possível verificar como os resultados das tarefas da triagem são integrados aos dados levantados na anamese e aos dados da avaliação neuropsicológica realizada posteriormente (caso 1), ao conjunto de sintomas que a criança apresentou (caso 2) bem como aos resultados de neuroimagem, estabelecendo relações entre possíveis disfunções observadas e áreas cerebrais afetadas (caso 3).

\section{Caso 1}

D. foi avaliado em 2006, sexo masculino, com 6 anos de idade. A queixa apresentada pela família durante a anamnese englobava agitação, desobediência, recusa em seguir regras e exposição a situações de risco, sem aparentar noção das consequiências de seus atos. Os comportamentos observados na triagem diagnóstica cor- 


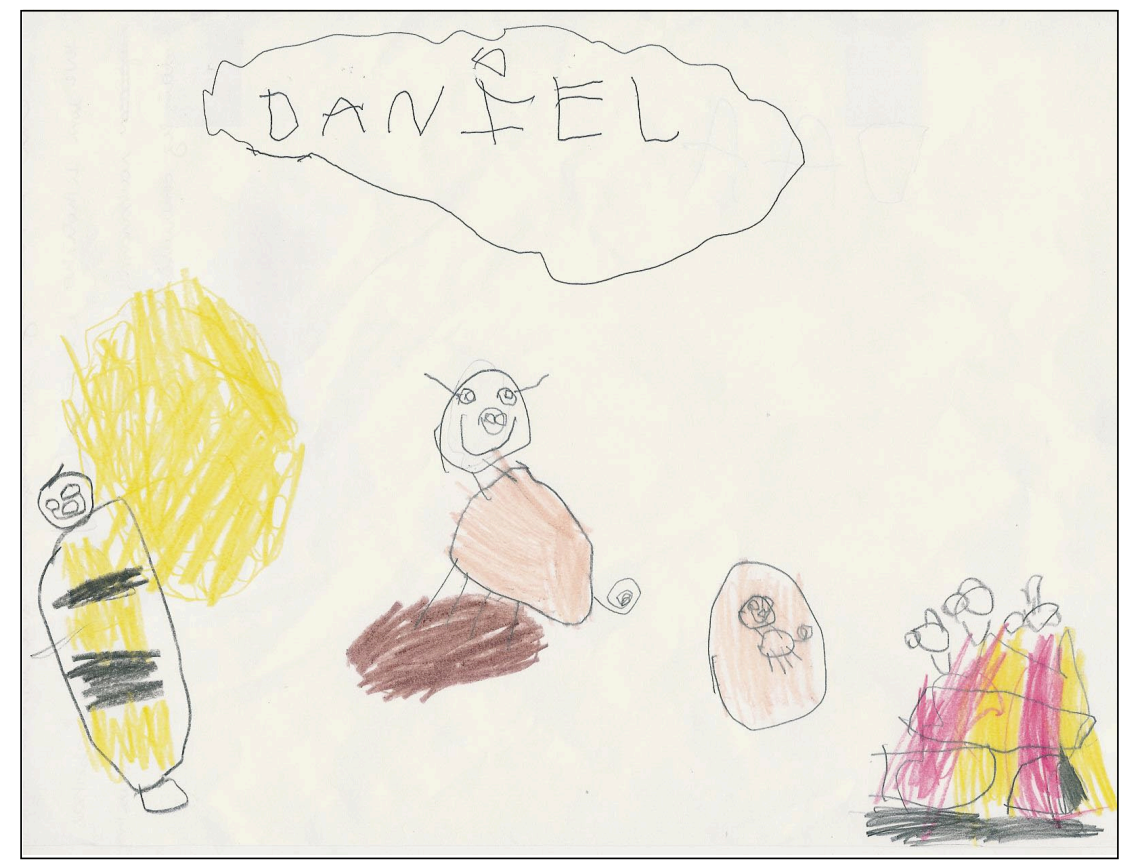

Figura 1. Caso 1

"Era uma vez um porquinho que um dia teve um filhotinho e teve um OVO bem grande, daí as abelhas roubaram, daí o policial pegou e roubou das abelhas e daí fez churrasquinho das abelhas e acabou".

roboraram com a fala dos pais, visto que a criança mostrou-se questionadora, não respeitou as regras, falando alto e fazendo barulho durante as atividades em grupo.

$\mathrm{O}$ desenho e a estória contada pela criança mostram a sua dificuldade em seguir as regras do ambiente e seu comportamento de oposição, visto que os personagens roubam uns dos outros, e a figura de autoridade (policial) apesar de roubar aplica uma medida punitiva, severa.

De acordo com os dados colhidos na Triagem Diagnóstica, a hipótese inicial era de um quadro de Transtorno do Déficit de Atenção/Hiperatividade. Assim, conduziu-se a avaliação neuropsicológica e clínica, mas também a avaliação familiar. Diversos estudos têm apontado que a avaliação das crianças com TDA/H deve ser de natureza ampla e multimodal, de forma a capturar a variabilidade situacional, pois a disfunção da criança está de alguma forma influenciada pelos padrões disfuncionais da interação familiar. Desta forma, é aconselhável voltar-se para a gama completa de contextos potencialmente relevantes, empregando-se enfoques multiderivados (Bastos, Urpia, Pinho, \& Filho 1999).

Constatou-se na avaliação neuropsicológica, que o nível intelectual global da criança se situa acima de sua faixa etária, assim como sua capacidade de manipular informações verbais. No curso da avaliação, D. questionou regras e tendeu a não cumpri-las, sendo necessário constantemente orientá-lo na execução das tarefas e delimitação de limites, da mesma forma como se apresentou na triagem diagnóstica.

A atenção, tanto sustentada, quanto seletiva, foi a função de maior comprometimento, ele se esquivou de atividades que dependiam de atenção visual seletiva e sustentada.

Em relação aos aspectos familiares, os pais apresentaram dificuldade em impor limites à criança havendo em muitos momentos troca de papéis e, assim, fragilidade na hierarquia. Os comportamentos opositores apresentados por D. foram compreendidos como também reativos ao contexto familiar.

D. preencheu os critérios diagnósticos de acordo com o CID-10 para Transtorno do Déficit de Atenção/Hiperatividade, e com relação aos aspectos comportamentais foi sugerido que tanto a família quanto a escola estabelecessem regras e limites claros e objetivos.

\section{Caso 2}

B. G. S., avaliada em 2005, sexo feminino, 12 anos de idade. $\mathrm{Na}$ anamnese a queixa apresentada foi de dificuldade em se relacionar com os colegas na escola e difícil comunicação em casa. Segundo a mãe, B. mudava rápido de atividades, não prendendo a atenção em uma tarefa por muito tempo. A família suspeitava de hiperatividade. O histórico mostra alguns dados bem relevantes: a mãe cita que não amamentou, pois logo que a filha nasceu o avô materno morreu. Por ser considerado um bebê quietinho e tranqüilo, a mãe a deixava de lado e ficava com a filha mais velha que passou a apresentar crises de ciúmes, enurese e gagueira após o nascimento de B. A mãe relatou ainda que a filha sempre tinha o hábito de pegar coisas dos outros, tais como dinheiro, material escolar dos colegas e coisas da irmã. A criança apresentava compulsão alimentar e por compras e perda 
do interesse com facilidade. Todos os critérios do DSMIV para transtorno de atenção e hiperatividade foram preenchidos em questionário respondido pela mãe.

$\mathrm{Na}$ triagem diagnóstica, no entanto, foram observados comportamentos muito retraídos, acompanhados de tom de voz baixo, concentração bastante adequada, pois B. ficou bastante tempo realizando seu desenho, com pouca interação com o grupo durante as atividades, mas com aceitação adequada das regras estabelecidas. O desenho e estória contada pela criança foram reveladores.

Durante a discussão em equipe frente aos dados oriundos da Triagem Diagnóstica, as impressões derivadas do contato da equipe com a criança foram de tristeza e de morte iminente, a profissional que estava acompanhando-a no grupo surpreendeu-se com a queixa da mãe. O desenho mostra também esses sentimentos que permearam a equipe profissional. Nossa hipótese gerada foi de que não seria um quadro de TDA/H e sim problemas emocionais, assim o foco da avaliação se deu nesses aspectos. De fato, a avaliação neuropsicológica e clínica não indicaram qualquer evidência de TDA/H. No que se refere ao enfoque emocional, vimos que durante todo o processo de avaliação B. mostrou-se calma e colaborativa, interessando-se mais nas atividades quando estimulada. Muitas vezes durante a execução das tarefas verbalizava com certa timidez, porém era assertiva nas respostas revelando facilidade no que era solicitado. B. apresentava uma auto-estima rebaixada e sinais de depressão, com significativo aumento de peso no último ano.

A avaliação da dinâmica familiar mostrou que havia um vínculo maior com sua irmã mais velha e certo distanciamento dos outros irmãos e pais, sendo o relacionamento com a mãe o mais conflituoso. Pelo fato de ser vista como a "criança problema", ocorreu um aumento de sentimentos de inadequação e não pertencimento ao grupo familiar e social. Os pais demonstravam dificuldade em estabelecer regras e limites aos filhos. Os conflitos e dificuldades interferiam na qualidade de relação entre os membros, afetando conseqüentemente o comportamento dos outros filhos também. A família demonstrava disponibilidade para receber orientações, por isso foram encaminhadas à terapia familiar. Atualmente B, recebeu alta e somente a mãe permanece em terapia.

Dessa forma, vimos que a triagem diagnóstica se mostrou essencial no estabelecimento da hipótese inicial e na conseqüente condução do processo de avaliação da criança.

\section{Caso 3}

L. Z. M. avaliado em 2005, sexo masculino, 11 anos de idade. Segundo informações da mãe a criança apresenta dificuldades na escola, para fazer as lições em sala de aula e na escola, reação com comportamentos agressivos quando contrariado, "nervoso" e recusa em freqüentar aulas de reforço. Apresenta comportamento agressivo em qualquer lugar, tem compulsividade para gastos de dinheiro, devido a esses comportamentos a criança não tem muitos amigos. No $7^{\circ}$ mês gestacional a mãe teve problemas de saúde e perda de peso. Após o parto foi detectada hidrocefalia, sendo internado na unidade de tratamento intensivo (UTI) por uma semana, com 16 dias



Figura 2. Caso 2

A guerra

"Houve uma época onde pessoas morriam por causa de guerras absurdas por motivos que nem sempre era muito importante, mas pessoas que vinham de outros paises com costumes diferentes achavam que eles podiam mudar tudo, mas quanto mais guerra mais as pessoas morriam". 


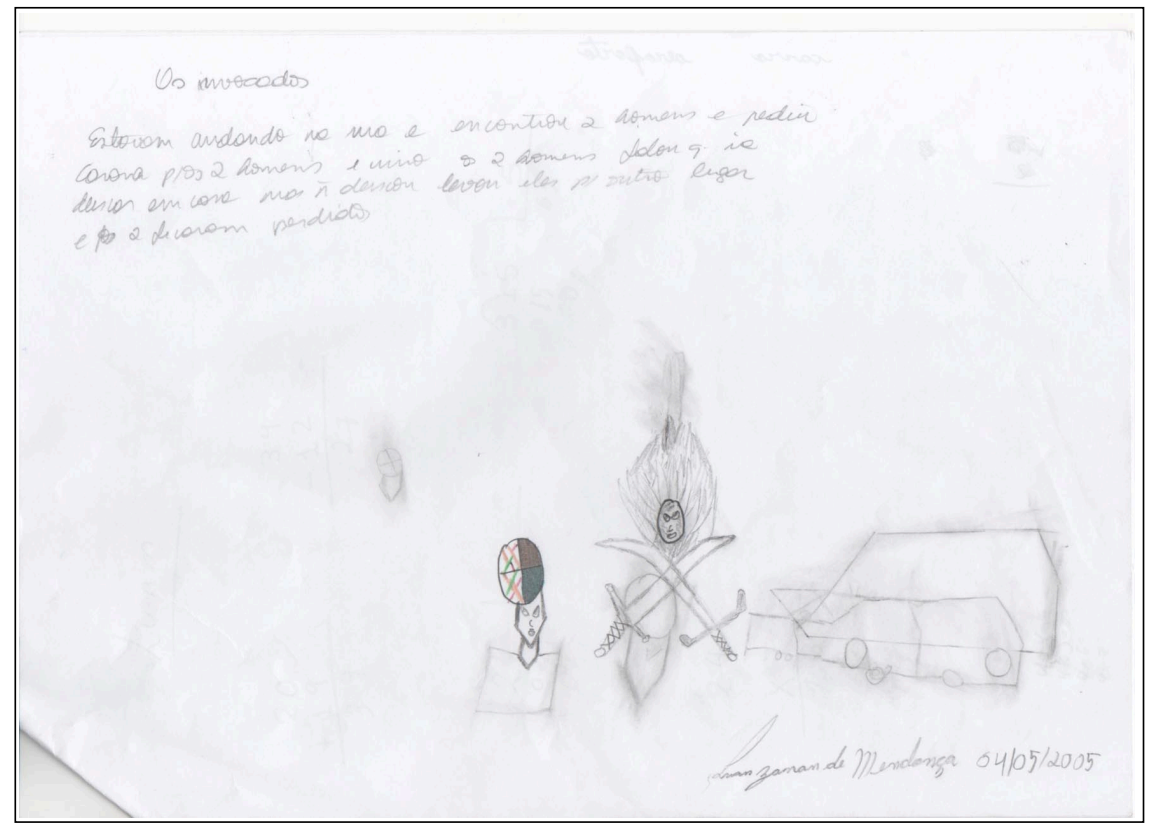

Figura 3. Caso 3

Os invocados

"Estavam andando na rua e encontrou dois homens e pediu carona para os dois homens e nisso os dois homens falou que ia deixar em casa, mas não deixou e levou eles para outro lugar e os dois ficaram perdidos".

colocou a válvula de drenagem e teve recuperação rápida do quadro de hidrocefalia, com 5 anos retirou a válvula e realizou tomografia. $\mathrm{Na}$ anamnese, segundo informações da mãe, "o médico disse que somente ficou uma cicatriz do lado esquerdo". Não foram detectadas alterações no desenvolvimento neuro-psico-motor.

$\mathrm{Na}$ triagem diagnóstica, observou-se que L. se recusou a realizar atividades e mostrou-se retraído, com pouca interação no grupo. O desenho realizado por ele, assim como a estória, corroboram claramente com a queixa.

No dia da triagem diagnóstica a mãe não trouxera os exames realizados anteriormente. Observamos que, muitas vezes, os profissionais da área de saúde se deparam com informações muito vagas que os pais trazem, ou que estes minimizam um problema, pois a mãe referia que o problema ocorrido no momento do nascimento não

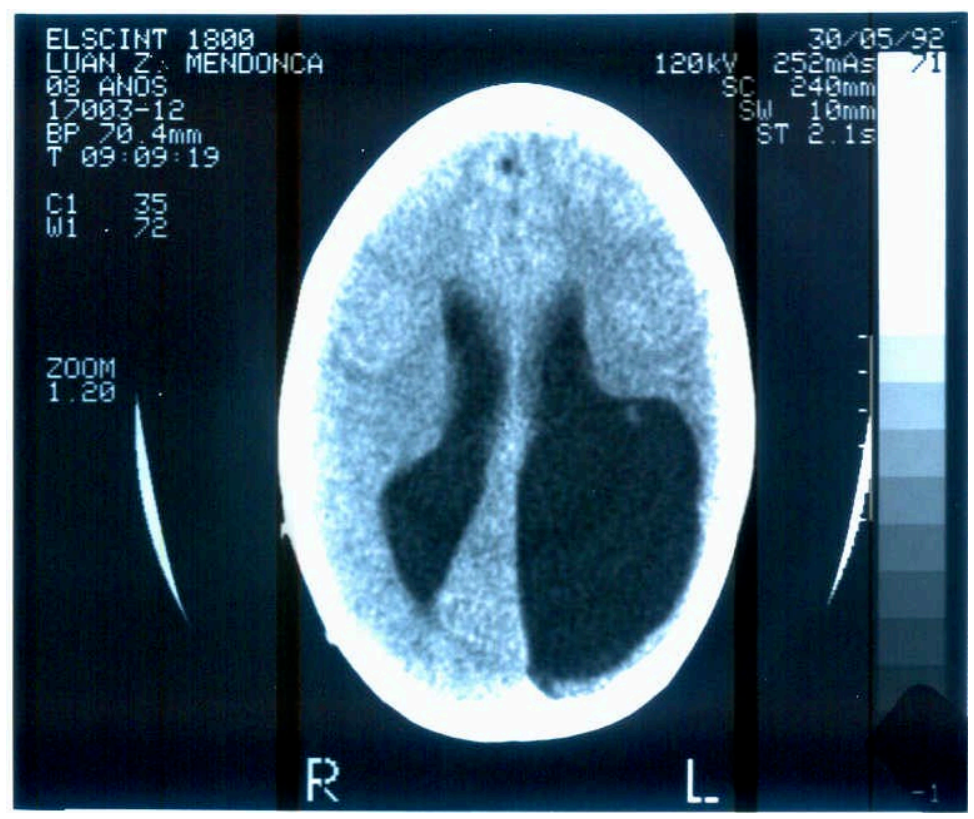

Figura 4. Ressonância magnética 
parecia ser a causa do comportamento da criança. O coordenador clínico observou que os profissionais que realizaram a anamnese também minimizaram esse fator e não solicitaram os exames, isso é algo que em nossa experiência tem se mostrado muitas vezes recorrente. Ou seja, os profissionais, principalmente da psicologia, justificam problemas de comportamento como essencialmente decorrentes de fatores ambientais. A ressonância magnética foi solicitada pelo coordenador clínico, a figura 4 mostra a "cicatriz do lado esquerdo".

Nota-se na ressonância magnética formação cística fronto-parieto-ocipital-esquerdo. Vemos que o desenho realizado por L. é altamente simbólico, representando exatamente a extensão da lesão. Ele retrata uma cabeça com um dos lados bem escuro, local da lesão extremamente extensa. E ainda desenha uma cabeça separada por duas espadas, o que pode simbolizar a separação mente/corpo, retratando sua dificuldade em controlar seu comportamento. A avaliação revelou um Transtorno Opositor/Desafiante decorrente da lesão cerebral. A literatura tem demonstrado que muitas alterações de personalidade são decorrentes de condições neurológicas (Beltrami et al., 2006). O DSM-IV caracteriza que como etiologia de alterações de personalidade devida à condição médica geral, inclui-se o trauma de crânio, patologias vasculares, neoplásicas, degenerativas, endocrinológicas, epilepsia, além de medicamentos, drogas e intoxicação por metais pesados, entre outras. A maior parte dos estudos referentes à mudança de personalidade em adultos (descrições de caso ou estudos de grupo) diz respeito a lesões de lobo frontal. Na criança, há, entretanto, padrões específicos vinculados à lesão temporal (epilepsia do lobo temporal), parietal direita (alexitimia em adultos) ou frontoparietal direita como timidez excessiva chegando à esquizoidia em crianças com lesão precoce (Beltrami et al., 2006).

\section{Discussão}

De acordo com nossa pesquisa em bases de dados, inclusive internacionais, observamos uma lacuna na área que envolve o estudo de processos sistematizados e estruturados de diagnóstico infantil envolvendo equipes interdisciplinares.

Avoglia (2006) aponta que em sua pesquisa em uma clínica escola, no tocante ao psicodiagnóstico, poucas mudanças ocorreram quanto à sequiência do processo, aos instrumentos utilizados e ao número de sessões, num período de 18 anos. Sugere a visita familiar e a escolar, como práticas complementares no procedimento de diagnóstico psicológico.

Acreditamos que visitas a família e a escola são modelos ideais, que contribuiriam com dados potenciais, mas infelizmente ainda estão longe do alcance das instituições públicas de saúde, pois há limitações estruturais, de profissionais e até mesmo geográficas.
A utilização do procedimento de triagem diagnóstica interdisciplinar promove a criação de hipóteses que por sua vez, guiam o processo de avaliação permitindo o direcionamento da avaliação de forma efetiva.

Considerando fatores como: redução do tempo de avaliação, diminuição da possibilidade de desgaste emocional do paciente (consulta com diferentes profissionais, sem diagnóstico), diagnóstico integrado, e o âmbito financeiro (população de baixa renda), pode-se pensar que a implementação deste procedimento em serviços ambulatoriais propicia benefícios amplos que envolvem não só a redução de custos, como também a humanização do atendimento ao paciente (Carey \& Konkol, 2001).

Nos casos que descrevemos verificou-se que a triagem diagnóstica teve seu valor tanto ao gerar informações coerentes com a anamnese dos pais, como no caso 1 no qual em decorrência do quadro de TDAH a criança apresentava problemas de comportamento. A criança, D., conseguiu elaborar seu desenho com um grafismo num nível de desenvolvimento adequado a sua idade, mas pode haver nesses quadros imaturidade no grafismo, falta de planejamento e organização no uso do lápis e papel, distúrbios motores como uso de objetos, escrita, etc, atrasos de linguagem como dislalias ou distúrbios de ritmo (Barkley 2008; Rohde, \& Mattos, 2003), os quais podem ser observados através do Protocolo de Triagem Diagnóstica.

Mas também nos casos em que o comportamento observado pelos profissionais em interação com a criança não coincidia com o relato da família, pois até mesmo a partir dessa diferença se faz possível o estabelecimento de hipóteses, como no caso 2 , no qual a queixa da mãe era diferente do comportamento demonstrado pela criança no grupo. Aspectos como timidez e interação com outras crianças, em triagens individuais não são possíveis de serem avaliados "in locu", mas apenas através de dados fornecidos.

No caso 3, apesar da queixa ir de encontro ao observado, a mãe focou sua fala nos aspectos de agressividade e dificuldade escolar, sendo que os comportamentos retraídos e a dificuldade de interagir com outras crianças não foram tão abordados. Porém, foram vistos claramente durante a triagem diagnóstica, dados compatíveis com o quadro lesional, ou seja, L. apresentou conhecimento de cores e percepção sensorial, sem dificuldades de nomeação e compreensão verbal, bem como o tônus e motricidade (postura, gestos, preensão), capacidade de imitar, expressar e interiorizar suas emoções, mas com dificuldades para formar vínculos, irritado, agressivo e impulsivo, por vezes com baixa tolerância à frustração. Não foi possível avaliar formalmente os aspectos neuropsicológicos, não permitindo dados mais precisos quanto aos aspectos cognitivos, mas notou-se que a criança não apresentava indicadores de déficit cognitivo, que pode ser visto pelo desenvolvimento do grafismo. As lesões dorsolaterais relacionam-se basicamente a déficits cogni- 
tivo-intelectuais, enquanto que lesões orbitomediais vinculam-se principalmente à alteração de personalidade, humor e comportamento (Beltrami et al., 2006).

Em síntese, gerar e criar situações de experimentação novas, de acordo com os vários sintomas envolvidos e investigados é abrir-se para a criatividade qualitativa que inclui e integra os procedimentos científicos e padronizados de avaliação. $\mathrm{O}$ acolhimento e disponibilidade que é oferecido ao examinando são também diferenciais consideráveis neste primeiro contato (Miranda, 2006). Assim nossas avaliações, apesar de protocolares, não são estáticas, não partem da separação entre critérios subjetividade, objetividade, qualitativo, quantitativo, mas do sentido unificado e complementar destes termos. A triagem diagnóstica, assim, pode ser pautada na observação qualificada e cuidadosa do examinador.

\section{Referências}

Avoglia, H. R. C. (2006). Avaliação psicológica: A perspectiva sócio-familiar nas estratégias complementares à prática clínica infantil. Tese de Doutorado não-publicada, Instituto de Psicologia, Universidade de São Paulo, SP.

Barkley, R. A. (2008). Transtorno de déficit de atenção/ hiperatividade: Manual para diagnóstico e tratamento (3. ed.). São Paulo, SP: Artmed.

Bastos, A., Urpia, A., Pinho, L., \& Filho, N. (1999). O impacto do ambiente familiar nos primeiros anos de vida: Um estudo com adolescentes de uma invasão de Salvador, Bahia. Estudos de Psicologia, 4(2), 239-271.

Beltrami, M. C., Mello, C. B., Miranda, M. C., Sinnes, E. G., Feldman C., Barbosa, T., et al. (2006). Mudança de personalidade após lesão de hemisfério cerebral direito. In C. B. Mello, M. C. Miranda, \& M. Muszkat (Eds.), Neuropsicologia do desenvolvimento: Conceitos e abordagens (pp. 237-247). São Paulo, SP: Menmon.

Carey, P. F., \& Konkol, R. J. (2001, October). Neuropsychology: Adaptation for a busy pediatric neurology clinic in a managed care setting. Paper presented at the meeting of the Child Neurology Society, Victoria, BC.

Costa, D., Azambuja, L., Portuguez, M., \& Costa, J. (2004). Neuropsychological assessment in children. Jornal de Pediatria, 80(2), 111-116.

Cunha, J. A. (2000). Fundamentos do psicodiagnóstico. In J. A. Cunha, Psicodiagnóstico (5. ed., Vol. 5, pp. 23-31). Porto Alegre, RS: Artmed.

Efron, A. M., Fainberg, E., Kleiner, Y., Sigal, A. M., \& Woscoboinik, P. (1976). La hora de juego dianóstica. In M. L. Ocampo, Las técnicas proyectivas y el proceso psicodiagnóstico (4. ed., Vol. 1, pp. 195-221). Buenos Aires, Argentina: Nueva Visión.

Gilmour, J. (2005). Specialist neuropsychological assessment procedures for children and adolescents. Psychiatry, 7(6), 246-252.

Mèredieu, F. (2006). O desenho infantil (A. Lorencini \& S. M. Nitrini, Trads., 11. ed.). São Paulo, SP: Cultrix.

Miranda, M. C. (2006). Avaliação neuropsicológica quantitativa e qualitativa: Ultrapassando a psicometria. In C. B. Mello, M. C. Miranda, \& M. Muszkat (Eds.), Neuropsicologia do desenvolvimento: Conceitos e abordagens (pp. 127 143). São Paulo, SP: Menmon.
Miranda, M. C., \& Muszkat, M. (2007). A experiência de um centro de diagnóstico e pesquisa em reabilitação na infância (NANI). In Neuropsicologia e inclusão: Tecnologias em (re)habilitação cognitiva (pp. 61-68). São Paulo, SP: Artes Médicas.

Rohde, L. A., Barbosa, G., Tramontina, S., \& Polanczyk, G. (2000). Transtorno de déficit de atenção/hiperatividade. Revista Brasileira de Psiquiatria, 22(Supl. 2), 7-11.

Rohde, L. A., \& Mattos, P. (Ed.). (2003). Princípios e práticas em TDAH. São Paulo, SP: Artmed

Santos, M. A. (1987). O psicodiagnóstico infantil em grupo: Uma experiência em instituição. Arquivos Brasileiros de Psicologia, 39(2), 3-17.

Souza, I., Serra, M. A., Mattos, P., \& Franco, V. A. (2001). Comorbidade em crianças e adolescentes com transtorno do déficit de atenção. Arquivos de Neuro-Psiquiatria, 59(2B), 401-406.

Teodoro, J. C. O., \& Horta, L. R. (2004). A importância das oficinas psicopedagógicas no processo diagnóstico. Psicologia e Argumento, 22(38), 73-76.

Trinca, W. (1984). Diagnóstico psicológico: A prática clínica. São Paulo, SP: EPU.
Recebido: 19/09/2007 $1^{a}$ revisão: 05/12/2007 $2^{a}$ revisão: $11 / 12 / 2008$ $3^{a}$ revisão: $16 / 12 / 2008$ Aceite final: 17/12/2008 